\title{
Characteristic of Organic Thin Film Depending on Carbon Content by Fourier Transform Infrared Spectra and X-ray Diffraction Pattern
}

\author{
Teresa Oh
}

\begin{abstract}
School of Electronics and Information Engineering, Cheongiu University; Cheongin 360-764, Korea. E-mail: teresalacjuac:kr
\end{abstract} Recened,Jamtan 17, 2007

Key Words : FTIR spectra, X-ray diffraction pattern, Si-O-C bond, Si-C] Is bond

Recently, organic semiconductors have attracted considerable attention to flexible electric application using lowdielectric (low-k) materials or organic thin film transistor. Conjugate polymers derive their semiconduction properties by having delocalized $\pi$-clectron bonding along the polymer chain. The $\pi$ and $\pi^{*}$ orbitals form delocalized valence and conduction wave functions, which support mobile charge carriers. ${ }^{1-3}$ One of the next candidates as low-k materials is SiOC film, which posses a lower dielectric constant due to the presence of lighter $\mathrm{C}$ and $\mathrm{H}$ atoms, as opposed to $\mathrm{Si}$ and $O$ atoms., Pentacene material as an organic conductor has been widely used in organic thin film transistors (OTFTs). However, in comparison with inorganic semiconductors, the electric properties of organic semiconductors are relatively little known. Fspecially, pentacene growth depends absolutely on the surface's properties on gate insulator due to the organic reaction. ${ }^{5-7}$ Therefore, it is important to understand the underlying organic molecular reaction between inter-layers. ${ }^{8-1 / 1}$ The mobility of pentacene increases dramatically on the hybrid type insulators, which is required an jonic bonding during the reaction. Because it's macrostructure becomes stable and the high degree of the amorphous structure. Finally the dielectric constant increases at the hybrid type sample and the leakage current also decreases. 11.12

To make the $\mathrm{SiO}_{2}$ film with hybrid properties, the samples were soaked in dilute $n$-Octadecyltrichlorosilane (OTS) solution to treat the surface. The ratio of the mixed solution of chloroforn $\left(\mathrm{CHCl}_{3}\right)$ and hexane was 300:700. and OTS was injected using a micropipet. The OTS solution was made from OTS:chloroform:hexane $=x: 300: 700(x=1-5)$. It was prepared a dilute OTS solution of $0.1-0.5 \%$. OTS $\left(\mathrm{CH}_{3}\left(\mathrm{Cl}_{2}\right)_{17} \mathrm{SiCl}_{3}\right)$ has an organic composition with many alkyl groups, therefore, the film treated using $0.1 \%$ OTS has more hybrid properties than that treated using $0.5 \%$ OTS. The $\mathrm{SiO}_{2} / \mathrm{Si}$ wafers were soaked in the prepared solution for $30 \mathrm{~min}$. Then the surface was cleaned for $5 \mathrm{~s}$ in a mixed solution of chloroform and hexane with the ratio of $300: 700$ and annealed in a vacuum chamber at $150^{\circ} \mathrm{C}$ for $1 \mathrm{~h}$.

Figure 1(a) shows the FTIR spectra in the full range from 600 to $4000 \mathrm{~cm}$ ' of the OTS-treated $\mathrm{SiO}_{2}$ film with various OTS-treatment contents from 0.1 to $0.6 \%$. Generally, an organic compound has its $\mathrm{CH}$ peak near $2900 \mathrm{~cm}$ ', but these samples do not have the $\mathrm{CH}$ peak near $2900 \mathrm{~cm}$ '. Therefore, OTS-treated $\mathrm{SiO}_{2}$ films are hybrid-type materials,
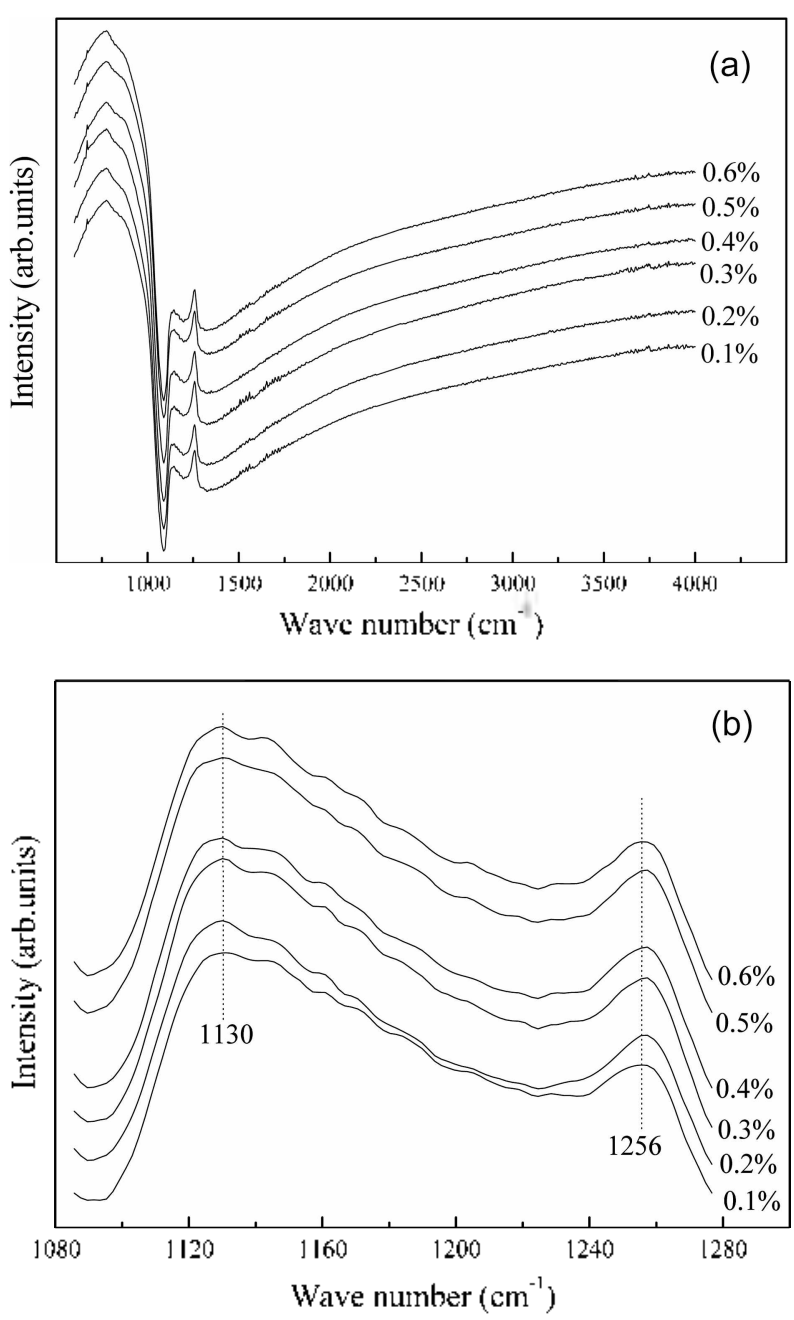

Figure 1. J"TIR spectra of OIS trealed SiO lilm according to the increase of OTS treated content. (a) FTIR spectra in the full range from 600 to $4000 \mathrm{~cm}$ '. (b) FTIR spectra in the narrow range from 1110 to $1280 \mathrm{~cm}^{-1}$.

such as SiOC films. The peak below $1100 \mathrm{~cm}^{1}$ is a $\mathrm{CH}-$ related bond. and the broad band from 1090 to $1280 \mathrm{~cm}^{1}$ is for the mixed bond attributed to the nucleophilic substitution reaction between $\mathrm{SiO}_{2}$ film and dilute OTS solution." Figure 1 (b) is the FTIR spectra of samples in the narrow range from 1110 to $1280 \mathrm{~cm}^{1}$. The peak at $1130 \mathrm{~cm}^{1}$ is for a $\mathrm{C}-\mathrm{O}$ related bond, and the peak at $1256 \mathrm{~cm}^{1}$ is related to a $\mathrm{Si}-\mathrm{CH}_{3}$ bond. Therefore, the broad band from 1090 to 1280 

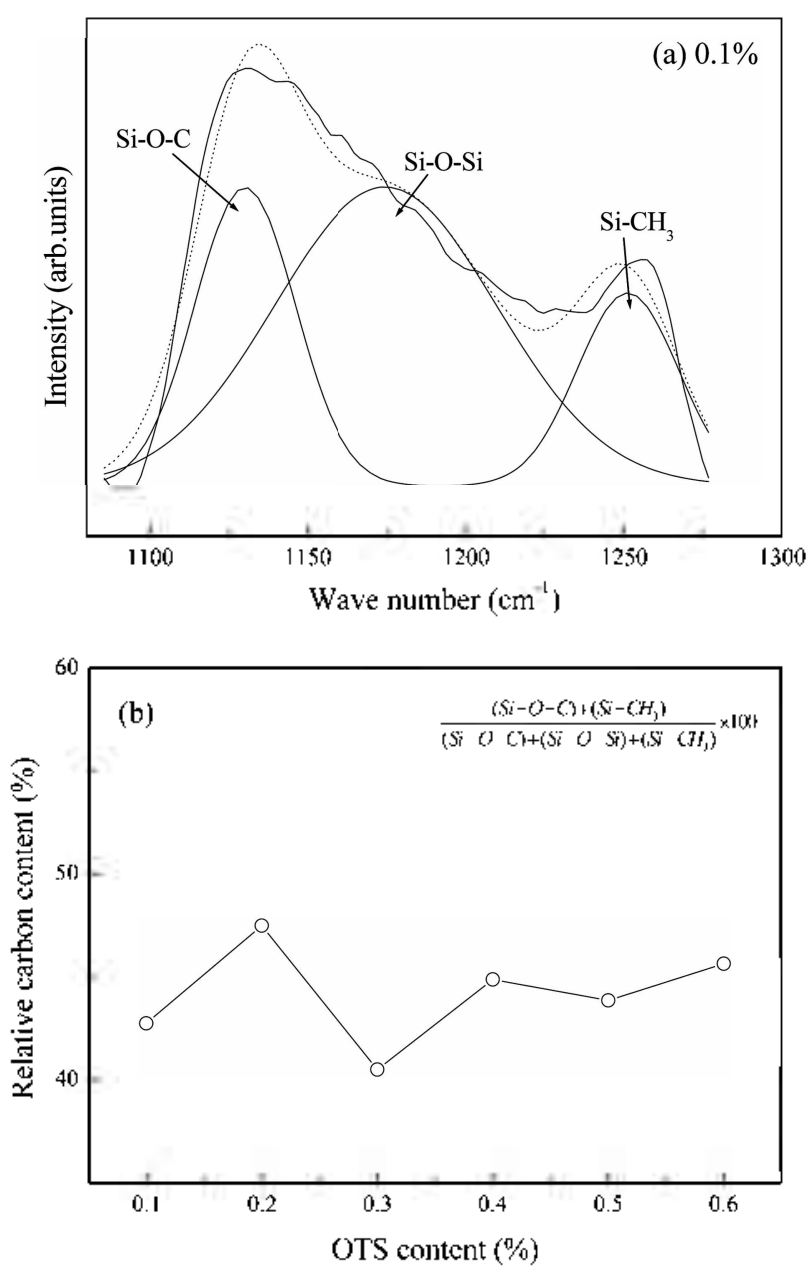

Figure 2. (a) Deconvoluted spectra for various OTS treated $\mathrm{SiO}_{2}$ film as shown in rig. l. (b). Relative carbon content.

$\mathrm{cm}^{\prime}$ is united the bond peak at $1130 \mathrm{~cm}$ ' to the bond peak at $1256 \mathrm{~cm}$ !

To research the relative bond contents, it was deconvoluted FIJIR spectrum in the range from 1090 to $1280 \mathrm{~cm}^{-1}$ by using a Gaussian peak fitting as shown in rigure $2(a)$. The deconvoluted spectrum consists of the first mode of the $\mathrm{Si}-\mathrm{O}-\mathrm{C}$ bond, the second mode of the $\mathrm{Si}-\mathrm{O}-\mathrm{Si}$ bond, and the third mode of the $\mathrm{Si}-\mathrm{CH}_{\hat{s}}$ bond. These bonds have different area or intensity according to the concentration of OTS mixed solution. The first mode of the $\mathrm{Si}-\mathrm{O}-\mathrm{C}$ bond is a result of the nucleophilic reaction between OTS mixed solution and $\mathrm{SiO}_{2}$ film. The second mode is induced in order that the high electronegative oxygen atom of $\mathrm{SiO}_{2}$ film reacts with OTS compound. The third mode of the $\mathrm{Si}_{-} \mathrm{CH}_{3}$ bond is a vibration mode of the terminal $\mathrm{Si}$ atom of the OTS compound. Finally, when the bond peak at $1130 \mathrm{~cm}$ ' and the bond peak at $1256 \mathrm{~cm}$ ' are combined, the bond structure of the final material shows a broad band from $1090 \mathrm{~cm}$ ' to $1280 \mathrm{~cm}^{1}$

Table 1 shows the relative carbon content for OTS-treated $\mathrm{SiO}_{2}$ film with increasing OTS content.

The relative carbon content is calculated from

$$
\frac{(\mathrm{Si} O \mathrm{C}) \perp(\mathrm{SiCH})}{(\mathrm{Si}-\mathrm{O}-\mathrm{C})+(\mathrm{Si}-\mathrm{O}-\mathrm{Si})+\left(\mathrm{Si}-\mathrm{CH}_{3}\right)} \times 100
$$

The relative carbon content obtained from eq. (1) is also the lowest for the $0.3 \%$-OTS-treated sample as shown in Figure 2(b).

Figure 3 shows the chemical shifts that depend on the peak position of the main $\mathrm{Si}-\mathrm{O}-\mathrm{Si}$ bond. The chemical shift originates from the effect of elongation or condensation of $\mathrm{CH}$ bonds due to the neighboring highly electronegative atom. The redshift is caused by the elongation of $\mathrm{CH}$ bonds by the electron-withdrawing group, but the blue shift causes the condensation of $\mathrm{CH}$ bonds owing to the electronreleasing group with abundant electrons. ${ }^{2}$ The final materials

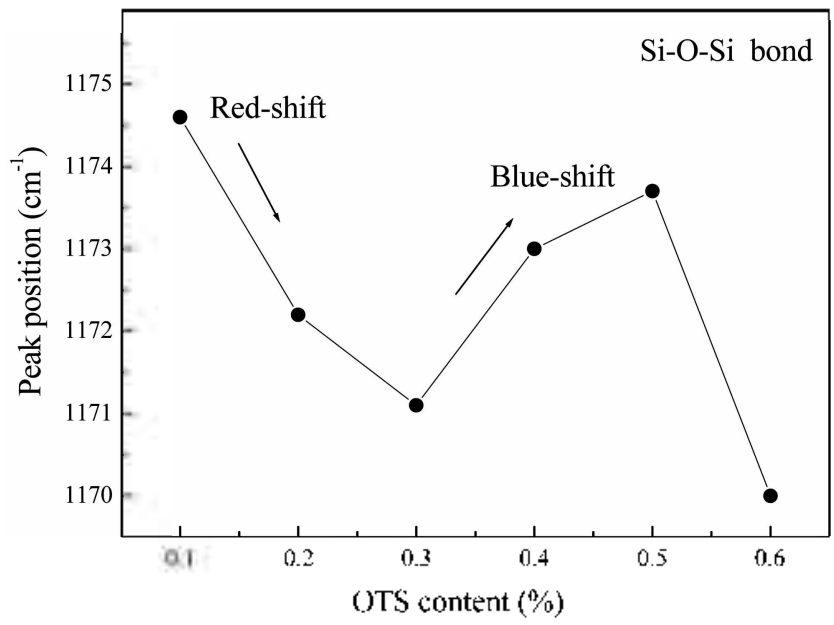

Figure 3. Chemical shift by the peak position of $\mathrm{Si}-\mathrm{O}-\mathrm{Si}$ bond.

Table 1. Relative carbon content for OTS-treated $\mathrm{SiO}_{2}$ film it ith increasing OTS content

\begin{tabular}{|c|c|c|c|c|c|c|c|}
\hline \multicolumn{2}{|c|}{ OLS-treatment content $(\%)$} & 0.1 & 0.2 & 0.3 & 0.4 & 0.5 & 0.6 \\
\hline \multirow{2}{*}{$\mathrm{SI}-\mathrm{O}-\mathrm{C}$} & area & 5.7304 & 5.9501 & 5.4822 & 5.9258 & 6.175 & 5.5662 \\
\hline & content $(\%)$ & 25.97 & 30.60 & 23.84 & 27.47 & 27.69 & 25.71 \\
\hline \multirow{3}{*}{$\mathrm{Si}-\mathrm{O}-\mathrm{Si}$} & areat & 12.628 & 10.189 & 13.674 & I1.888 & 12.514 & 11.767 \\
\hline & perak position $\left(\mathrm{cm}^{-1}\right)$ & 1174.6 & 1172.2 & 1171.1 & 1173.0 & 1173.7 & 1170.0 \\
\hline & $\operatorname{content}(\%)$ & 57.22 & 52.51 & 59,46 & 55.1 & 56.12 & 54.34 \\
\hline \multirow{2}{*}{$S 1-C .11$} & arca & 3.7109 & 3.2664 & 3.8402 & 3.7601 & 3.6108 & 4.3209 \\
\hline & content $(\%)$ & 16.81 & 16.83 & 16.7 & 17.43 & 16.19 & 19.95 \\
\hline \multicolumn{2}{|c|}{ Relative carbon content (\%) } & 47.278 & 47.49 & 40.55 & 44.9 & 43.88 & 45.66 \\
\hline
\end{tabular}




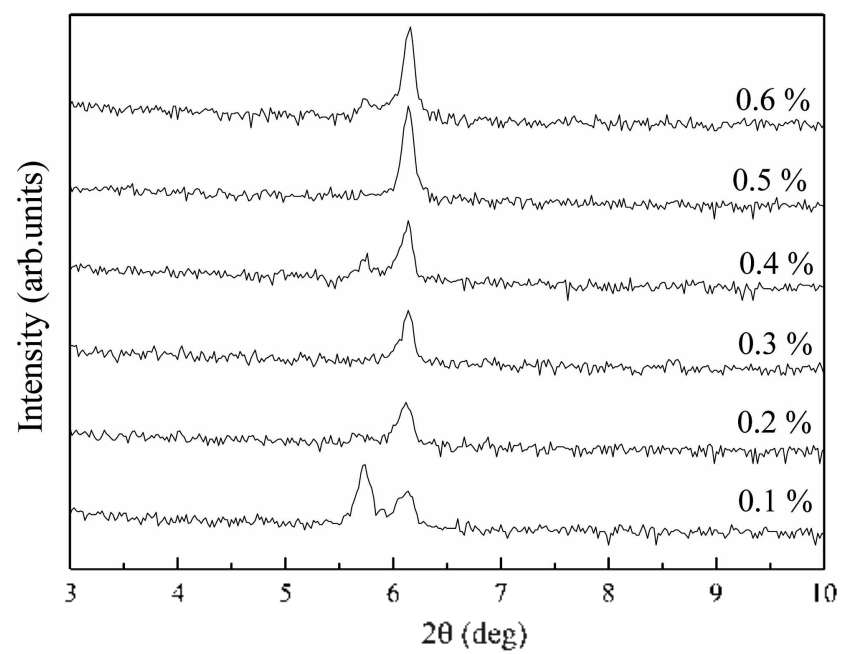

Figure 4. XRD patterns of samples with the increase of OTStreated content.

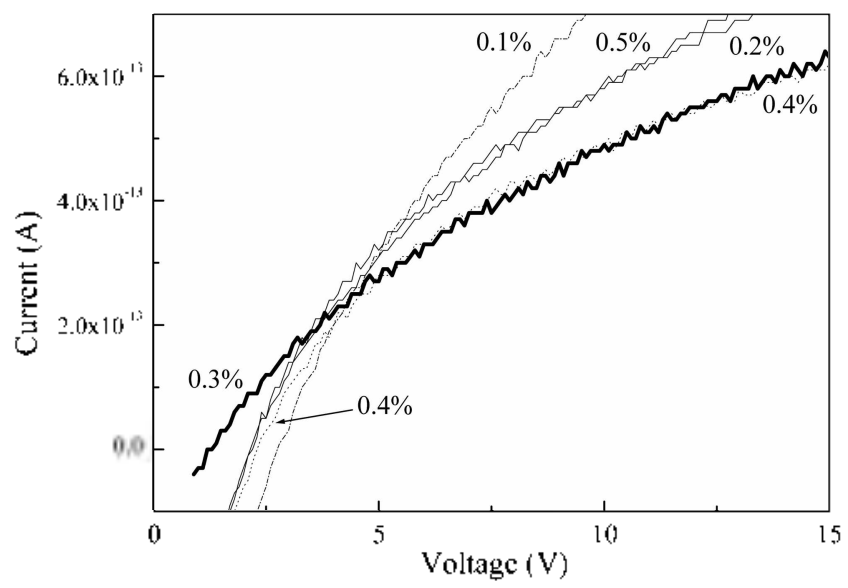

Figure 5. Surlace leakage cument of samples with the increase of OTS-treated content.

have a difference in surface energy depending on the chemical shift. The surface energy is related to the flatness of the film, and the surface energy decreases due to the effect of $\mathrm{CH}$ bond elongation. Consequently, a sample exhibiting redshift with low surface energy has good flatness, which is an important factor in thin films. The electrophysical properties of the redshift and the blueshift are also completely different as previous mentioned. From these results, it is confirmed that the $0.1-0.3 \%$-O']S-treated samples showed red shift and the $0.3 \%$-OTS-treated sample had the greatest redshift. The sample with increasing $0 \mathrm{lS}$-treatment content governed the blueshift.

Figure 4 shows the XRD patterns of the samples with increasing $O$ TS-treatment content. The $(00 \mathrm{I})$ peak near $6^{\circ}$ is related to the $\mathrm{Si}$ atom, and that of the $0.3 \%-0 \mathrm{TS}$-treated sample is narrow and low. However, other samples show high-intensity peaks or two peaks, which mean the high crystallization or mixed bonding structure.

Figure 5 shows the surface leakage current of samples with the increase of $\mathrm{O}$ ]S treated content. The $0.3 \%$-O [Streated sample has lower leakage current than that of any other samples. The voltage shift at zero current is also lower that any other samples. The above findings lead to conclude that the $0.3 \%$-OTS-treated sample has an amorphous structure, which is required as the low-k materials. "The low$\mathrm{k}$ inaterials such as $\mathrm{SiOC}$ film have an amorphous structure and decrease the dielectric constant due to the low polarization. ${ }^{11}$

In conclusion, OTS-treated $\mathrm{SiO}_{2}$ film was similar to hybrid type $\mathrm{SiOC}$ film, which consists of $\mathrm{Si}, \mathrm{O}$ and $\mathrm{C}$ atoms. The Fourier transform infrared spectra of the range from 1110 to $1280 \mathrm{~cm}^{\prime}$ in the OTS-treated $\mathrm{SiO}_{2}$ film consisted of $\mathrm{Si}-\mathrm{O}-\mathrm{C}, \mathrm{Si}-\mathrm{O}-\mathrm{Si}$, and $\mathrm{Si}-\mathrm{CH}_{3}$ bonds. The OTS-treated $\mathrm{SiO}_{2}$ film was involved in the chemical shifts of blue and red shifts, which was defined from the peak position of Si-O-Si bond. The sample of the dominant redshift showed the least amount of carbon content, which means the turn point of the variation of bonding structures.

\section{References}

1. IJideki. N.: Tokiyoshi. U.: Hiroyoshi. M.: Nkihiko, F.: Masarori. O. Jpr. J. Appl. $1 / 1$ ws. 2006. 45.2792 .

2. Hiroyuki. I. Jph. J. Appl. Phys. 2006. 45.1540.

3. Masahito. K.: Yoshiaki. I.: Kicko. H.: Kazuyuki. S. Thin Solid Films 2006. 509.149

4. Teresa. O. Jpn. J Appl. Ph:s 2005 H. 4103.

5. Knipp. 1).: Street. R. A. J. Kon-crystalline Sofids 2004. 338. 595.

6. Nathalie. V.: Mario. S.: Winl. D. Fetrohedon Lett. 2004. 45.7287.

7. Kymissis. I.: Dimitrakopoulos. D. C.: Purushothaman. S. /EEE Transations on Electron Devices 2001. 48.1060

8. Jac. 11, Y.: Min, K. K.: Ji. II, S.: IN'un, J. C.: Young. U. K. Bull. Korean (hem. Soc 2007, 29, 1097.

9. Chang. M. K. Bull. Korean ( Wem. Soc. 2016. 27. 2037.

10. Gerald. D. Surfoce Sience 2006. 600. 971

11. Teresa. O. IEEE Hansactions on Nunotechology 2006. 5. 23

12. Teresa. O. Jpm. J. Appl. Pins. 2005. f4. 8102. 